\title{
The impact of preoperative patient characteristics on the cost-effectiveness of total hip replacement: a cohort study
}

\author{
Matthias Vogl ${ }^{1,2^{*}}$, Rainer Wilkesmann ${ }^{3}$, Christian Lausmann $^{3}$ and Werner Plötz ${ }^{3,4}$
}

\begin{abstract}
Background: To facilitate the discussion on the increasing number of total hip replacements (THR) and their effectiveness, we apply a joint evaluation of hospital case costs and health outcomes at the patient level to enable comparative effectiveness research (CER) based on the preoperative health state.

Methods: In 2012, 292 patients from a German orthopedic hospital participated in health state evaluation before and 6 months after THR, where health-related quality of life (HRQoL) and disease specific pain and dysfunction were analyzed using EQ-5D and WOMAC scores. Costs were measured with a patient-based DRG costing scheme in a prospective observation of a cohort. Costs per quality-adjusted life year (QALY) were calculated based on the preoperative WOMAC score, as preoperative health states were found to be the best predictors of QALY gains in multivariate linear regressions.

Results: Mean inpatient costs of THR were 6,310 Euros for primary replacement and 7,730 Euros for inpatient lifetime costs including revisions. QALYs gained using the U.K. population preference-weighted index were 5.95. Lifetime costs per QALY were 1,300 Euros.

Conclusions: The WOMAC score and the EQ-5D score before operation were the most important predictors of QALY gains. The poorer the WOMAC score or the EQ-5D score before operation, the higher the patient benefit. Costs per QALY were far below common thresholds in all preoperative utility score groups and with all underlying calculation methodologies.
\end{abstract}

Keywords: Health-related quality of life, Costs, Cost-effectiveness, Cost-utility, QALY, EQ-5D, WOMAC, Total hip replacement, Hip

\section{Background}

Because of scarce resources in health care systems and a concurrent increasing number of total hip replacements (THR) worldwide, cost-effectiveness and quality performance measures for THR are becoming more important [1]. With 295 THR per 100,000 inhabitants, Germany currently has the highest THR rate among European Union countries [2]. At over 210,000 operations, THR was among the top

\footnotetext{
* Correspondence: matthias.vogl@helmholtz-muenchen.de

${ }^{1}$ Helmholtz Zentrum München, German Research Center for Environmental Health, Institute of Health Economics and Health Care Management, P.O. Box 1129, Neuherberg 85758, Germany

2Ludwig-Maximilians-Universität München, Munich School of Management, Institute of Health Economics and Health Care Management \& Munich Center of Health Sciences, Munich, Germany

Full list of author information is available at the end of the article
}

10 surgeries performed in Germany in 2011 [3]. With an aging society, these numbers - and especially the number of revision THR - will increase further. Future supply, development, and innovation in THR will depend more and more on its cost-effectiveness for certain patient groups [4]. Some National Health Service (NHS) trusts in the UK already prioritize patient groups based on patient-reported outcome measures (PROMs) to facilitate efficient and effective THR treatment $[5,6]$. The intense discussion on the necessity for and the benefit of the increasing number of THRs can be facilitated by this recent empirical evidence on the average cost-effectiveness of THR in Germany, which has not been analyzed to date. Thus, we apply a joint evaluation of hospital costs and health outcomes at the patient level to enable comparative effectiveness research 
(CER) based on the preoperative health state. CER provides medical and economic decision support in health care systems with scarce resources.

Currently, there are only separate analyses on the impact of preoperative characteristics on length of stay [7], Health-related Quality of Life (HRQoL) [8-17], and single THR cost studies $[18,19]$. Thus, the existing literature informs only on the overall costs and general resource use of THR patients [20,21]. Because of the high cost and health outcome differences in an international comparison of THR, a patient group specific cost-effectiveness analysis is necessary [19,22]. Thus, we calculate quality-adjusted life years (QALYs) for several preoperative WOMAC states. QALYs report the number of years gained in perfect health by measuring the difference in HRQoL before and after THR. For reasons of comparability and country specificity, we use three different concepts of costeffectiveness analyses from patient-reported health states: (1) a QALY calculation based on the UK population preference-weighted index to enable comparison with other studies; (2) a QALY-like calculation based on the German population experience-weighted index (EBQALY) to introduce the perspective of the general German population; and (3) a visual analog scale adjusted life year calculation (VAS-AL) to use the gold standard of health outcome measures - the VAS - in costeffectiveness analyses. With an activity-based allocation of costs calculated for each study patient, we calculate the cost utility of THR for each patient.

QALYs are used increasingly by policy supporting institutions such as the National Institute for Health and Care Excellence (NICE) to facilitate decision making [23,24]. With a CER based on the impact of preoperative patient characteristics on QALYs, we support prioritization and payment by results approaches in health policy and modeling approaches in research. Management interventions to provide cost-effective THR are supported by detailed costing related to preoperative patient characteristics. Thus, the aim of the study is to find preoperative patient characteristics that predict the cost-effectiveness of THR and quantify its impact on cost-effectiveness to support medical decision making based on preoperative patient groups.

\section{Methods}

\section{Study population}

From January to June 2012, 393 patients were eligible to participate, 387 THR patients participated in the baseline health state evaluation and 321 (82\%) patients participated in the follow-up. For 292 patients (74\%) we received full HRQoL information including all WOMAC and EQ-5D health measures and attributable, patient-based costing measures. Except for lack of patient consent, we had no exclusion criteria. The study was performed at an orthopedic hospital in Munich (Hospital Barmherzige Brüder München, university teaching hospital) and had approval from the ethics committee of Klinikum rechts der Isar, Technical University Munich. All patients followed a similar clinical pathway, which is independent of preoperative patient characteristics, to fulfill the prerequisite of the prognostic study design for patientgroup specific information on costs per QALY [25]. For most patients osteoarthritis was the major diagnosis (95.5\%); some had osteonecrosis, mechanical complications, or infections that led to THR as the major diagnosis. For 21 patients we had some missing data in covariates. Diagnostic tests showed that we can afford loosing those cases for regression analyses. As imputation could induce another bias in the analysis, we kept the reduced dataset for regression and worked with the full dataset in cost- and effectiveness analyses where a comprehensive set of covariates is not necessary.

\section{Study design}

The innovation in the study design is a detailed acquisition and combination of costs and HRQoL data at the patient level. While we measure costs with a standardized, patient-based DRG costing scheme [26], effectiveness is measured with a generic HRQoL instrument on five health dimensions (EQ-5D) [27] before (baseline) and 6 month after THR (follow-up) to enable change score models that are related to case-based costs and preoperative patient characteristics. In this single center, prospective observation of a cohort, we define a set of preoperative patient characteristics with an impact on HRQoL or costs in prior clinical studies [8-17] and shed light on THR cost-effectiveness for patients with different preoperative characteristics.

To calculate life expectancy, we used the life expectancy of each THR patient based on age and gender from the life tables of the federal statistical office [28] and multiplied them by the EQ-5D change scores to calculate QALYs, assuming that the change score remains constant during each patient's individual life expectancy. Based on literature recommendations, we discounted QALYs and costs of potential revision by 3.5\% [29]. On account of very low differences in HRQoL comparing primary and revision THR [30,31], and presumed similarity in the literature [5], we did not distinguish between primary and revision THR concerning HRQoL. Based on literature, we assigned a THR revision rate of $7.5 \%$ for the first 10 years and $1.5 \%$ for each following year $[5,32,33]$

We calculate the average cost-effectiveness ratio (ACER) for several THR groups compared with no intervention. In the medical literature, the ACER and the incremental cost-effectiveness ratio (ICER) are sometimes used interchangeably with each other, especially when 
the alternative to a procedure is only no intervention [21]. In familiar interventions such as THR, where the alternative is usually no intervention, empirical studies have shown that the ICER is not preferable to the ACER for medical decision making [34]. Thus, all costeffectiveness ratios in this paper refer to ACER.

\section{Measuring instruments}

Clinical practice guidance mentions reduced $\mathrm{HRQoL}$ as a limitation related to osteoarthritis [35]. The EQ-5D is a generic $\mathrm{HRQ} O L$ instrument, which generates an index value based on a formula with respect to the preferences and experiences of a country's population out of the five dimensions of mobility, self-care, usual activity, pain/discomfort, and anxiety/depression [27]. A 5-digit code made up of these five domains (each with 3 possible values: no problems, some problems, severe problems) allows 243 health states, which are evaluated based on three different methodologies to allow for comparability with U.K. and U.S. studies and concurrent country specificity [29]. Thereby the best health state is $1,1,1,1,1$ (no problems in each dimension) and the worst health state is 3,3,3,3,3 (severe problems in each dimension). The U.K. population preferenceweighted index uses a value for each 5-digit code that is based on the time trade-off (TTO) preferences of the general U.K. population [36]. The German population experience-weighted index uses the VAS results from the general German population to allocate a value to each 5digit state [27]. Additionally, the overall health state is measured using the VAS, which retrieves the overall health state on a $0-100$ scale in the study population. The German experience-weighted index and the VAS do not fully qualify for QALY calculation as they are not based on TTO and do not include health states worse than death. Thus, they do not conform to the common QALY definitions and are therefore called experience-based QALY (EB-QALY), when based on the German experience-weighted index, and VAS adjusted life years (VAS-AL), when based on the VAS scale. All EQ-5D calculations allow a comprehensive evaluation of the actual value of an intervention for the patient: it is a comparative effectiveness measure for HRQoL that is recognized as reliable, valid, and responsive in the literature $[37,38]$. The WOMAC score is a disease specific score that measures pain and dysfunction of the hip. To measure hip-specific outcome from a patients' perspective, we use the WOMAC with its three subscales on pain (5 sub-questions), stiffness (2 sub-questions), mobility (17 sub-questions), and an overall score based on the three subscales. To make the overall score comparable to EQ-5D results, we transformed WOMAC results to a $0-100$ scale where 0 is the poorest measure and 100 is the best measure. Each WOMAC question has a Likert scale from 0 to 10 . The WOMAC shows the best psychometric characteristics in THR specific questionnaires [39-41].

The costing scheme of the Institute for the Hospital Remuneration System (InEK) was introduced to calculate reimbursement rates for DRGs in a transparent and efficient way [42]. In 2011, 263 hospitals participated in the calculation [26]. It provides a detailed, patient-based cost accounting scheme, which is used by hospitals to participate in the reporting process that their reimbursement is based on. We use the InEK costing scheme to calculate case costs and analyze the impact of preoperative characteristics on resource utilization and case costs. Costs and resource use in the scheme are split into several costcategories (physicians, nursing, medical/technical staff, drugs, implants, other material, medical- and nonmedical infrastructure) and cost-centers (ward, operating room, anesthesia, intensive care, diagnostics/therapy, radiology, and laboratories). The cost breakdown allows a comparison with other THR costing studies in the U.S., the U.K., and other European countries [18,19,22].

\section{Statistical analysis}

Patient characteristics with potential impact on costeffectiveness are included in three subdomains: (1) sociodemographic factors, including age, gender, marital status, housing situation, kind of discharge, and kind of insurance; (2) medical factors, including BMI, major diagnosis, all frequent secondary diagnoses, the number of secondary diagnoses, ASA classification, Charlson Comorbidity Index, metabolic syndrome, all major procedures and frequent side procedures (e.g., use of cement), number of operations and procedures, number of operations on affected joint before hospital stay, major hip distortion, and preoperative hemoglobin value; (3) HRQoL, pain, function, and mobility before THR, measured by EQ-5D, WOMAC, and Harris Hip Score.

Spearman's correlation was used to examine the bivariate relation of independent variables to costs and QALYs. Covariates with a relation $(\mathrm{p}<0.05)$ were included in a multivariate linear regression analysis (OLS). OLS was used for cost and QALY analyses, as both were normal distributed. A backward selection method was used to determine the final set of covariates in the OLS on costs and QALYs. Covariates were considered relevant for $\mathrm{p}<0.05$. We provide descriptive statistics for cost and QALY gains separated by preoperative WOMAC groups, the most predictive preoperative patient characteristic according to OLS analysis. For patient differentiation we used the WOMAC as a standardized and specific, patient-based reporting measure. As WOMAC and EQ-5D are correlated we could not eliminate the "regression to the mean" issue [43], a general limitation of cohort studies when analyzing subgroups. Data analysis was performed using SPSS 21 software. 


\section{Results}

Some $58 \%$ of the study population was female, the average age was 68 years, and most patients had an ASA score of 1 or 2 and a Charlson Comorbidity Index of 0 or 1 (Table 1). Most patients received cementless primary THR with osteoarthrosis of the hip as the major diagnosis. Compared to the population in a large European Study that includes also a representative German sample [44], our population is slightly younger, has less secondary diagnoses (lower average Charlson Comorbidity Index), and patients have shorter length of stay and lower costs. $89 \%$ of patients were in the major DRGs for THR (I47A and I47B). Table 1 shows all the control variables and their correlation with costs and QALYs. Correlations were detected, e.g., for acute anemia, diabetes, depression, sleep disorder, major hip distortion, number of secondary diagnoses, number of operation and procedure codes, open reposition fracture, operations at joint before procedure, housing situation, health insurance, ASA score, and Charlson Comorbidity Index.

OLS regressions showed the relationship of several preoperative characteristics to inpatient costs and QALYs. The impact of WOMAC and EQ-5D was provided separately to avoid multi-collinearity. Both preoperative measures are correlated. For the grouping of QALY gains we used the WOMAC as it is most accepted among orthopedics and mostly used in day-to-day routines. Both preoperative scores have similar impact on QALY gains but low impact on inpatient costs, as patients were treated very similar. Generally, there was low variance in inpatient THR costs but the number of operation and procedure codes, the number of secondary diagnoses, health insurance, and revision THR had an impact on costs (Table 1). Mean costs of THR were $€$ 6,310 (95\% confidence interval $€ 6,160-€ 6,472$ ) with the highest costs for ward and operating room in the cost-center view and the highest costs for physicians, implants, and infrastructure in the cost category view (Table 2). Revision THR increases inpatient costs by $18 \%$. Average life expectancy of the study population is 17.57 years. Studies show that the probability of revision is $7.5 \%$ for the first 10 years after primary THR and $1.5 \%$ for each year thereafter [5,33], resulting in average lifetime inpatient costs of $€ 7,730$ for THR. The grouping by preoperative WOMAC score shows a trend that healthier patients cost less (Table 3).

Mean EQ-5D utility score change was 0.33 with the U.K. preference based value set as the underlying utility scores (preoperative 0.51; postoperative 0.84). With the German experience-based value set, EQ-5D utility score change was 0.22 (preoperative 0.54 ; postoperative 0.76 ). The VAS score change was 18.45 (preoperative 59.76; postoperative 78.22). Change scores were not affected by either gender or age. Bivariate analysis showed high correlation of preoperative WOMAC scores with QALYs gained. In a multivariate OLS analysis, the preoperative EQ-5D and WOMAC scores had the highest impact on the effectiveness of THR and therefore QALYs (Table 4). Thus, we provided QALY calculation for preoperative WOMAC groups. Among all preoperative characteristics, the preoperative WOMAC score suits best for payment by results approaches, modeling approaches, and management interventions to provide cost-effective THR.

QALYs gained using the U.K. preference based value set were 5.95. Lifetime costs per QALY were $€ 1,300$. Using the German experience-based value set as the underlying set for EQ-5D utility scores showed an EBQALY gain of 4.05 with $€ 1,908$ per EB-QALY. The VAS showed a VAS-AL gain of 3.43 and costs of $€ 2,256$ per VAS-AL. VAS results were divided by 100 to calculate VAS-AL and to be comparable with the U.K. QALYs and the German EB-QALYs. All three value sets for QALY and QALY-like calculation showed a large increase in QALY gains with a decrease in preoperative WOMAC scores, indicating that patients with poor WOMAC scores benefit most from THR (Table 3). QALY gains are higher when patients are less healthy. The separation of study participants into age groups showed that even the oldest age group, which naturally gains the fewest QALYs, had low QALY costs (Table 5). The economic perspective of QALYs is further correlated with direct medical pain and dysfunction scores, e.g., the Harris Hip Score (Figure 1), showing that physician based questionnaires can also be used for a health economics perspective.

\section{Discussion}

Multivariate regression analyses gave an overview of the actual drivers of cost-effectiveness in THR: costs were mainly increased by special procedures, such as excision/resection of the diseased bone and open reposition of fracture, or by revision (Table 4). Preoperative patient characteristics had no important and systematic impact on THR costs. On the effect side, some preoperative characteristics can impact health outcome significantly. Depression, reflux, and major hip distortion significantly reduce QALY gains (Table 4). A higher ASA score and revision compared with primary THR also significantly reduce QALY gains. Increased age and high EQ-5D scores reduce QALY gains the most. We have average THR costs of $€ 6,310$ with a $95 \%$ confidence interval of $€ 6,160-€ 6,472$, with a trend that healthier patients cost less (Table 3). In countries with similar purchasing powers to those in the U.S. or Europe - and where health insurance is available - costs are not the limiting factor when contrasting them with QALY gains in costeffectiveness analyses. Patient characteristics that affect 


\section{Secondary diagnoses, at least 10 times}

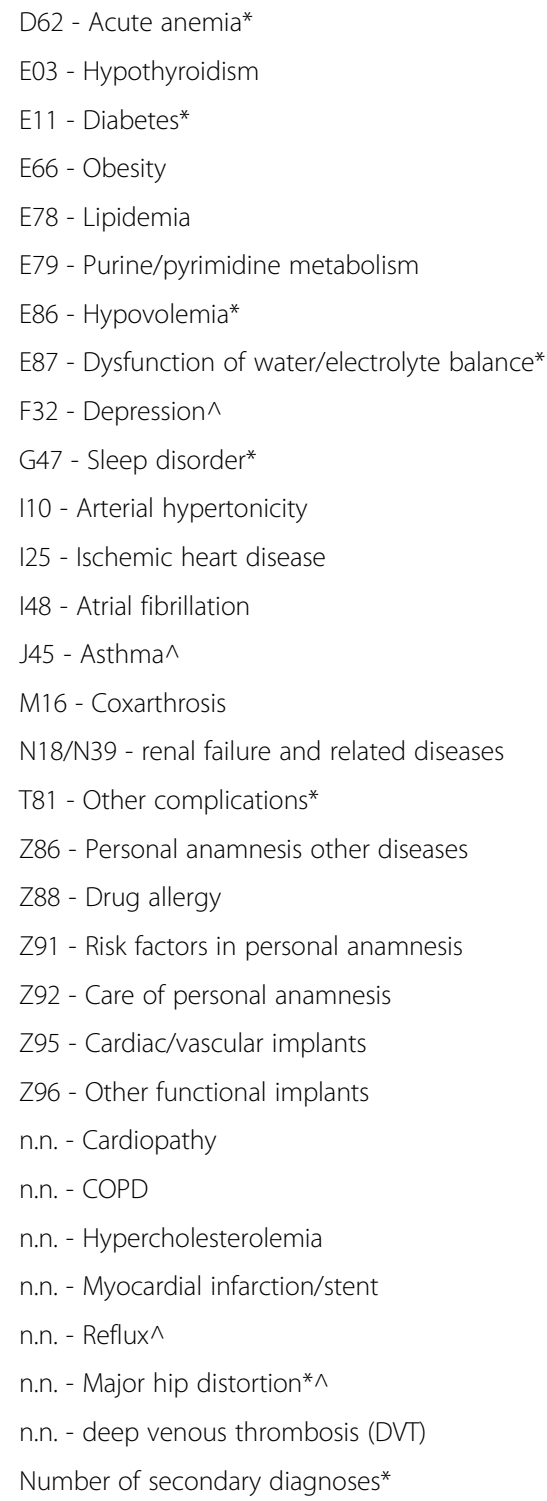

Operations and procedures, at least 5 times

5-782 - Excision/resection of diseased bone*

5-791 - Open reposition of fracture*

5-820 - Primary endoprosthesis (no revision)

5-821 - Revision*

5-829 - Other arthroplasty*

5-986 - Minimally invasive technique

8-919 - Acute pain relief

8-930/1 - Monitoring*

Number of operation and procedure codes*

$\begin{array}{rrr}5 & 1.7 & 2 \\ 6 & 2.1 & 2 \\ 281 & 96.7 & 2 \\ 10 & 3.4 & 2 \\ 10 & 3.4 & 2 \\ 271 & 93.4 & 2 \\ 5 & 1.7 & 2 \\ 30 & 10.3 & 2 \\ 2.4(1.2) & & 2\end{array}$


Table 1 Impact of relevant preoperative patient characteristics (Continued)

\begin{tabular}{|c|c|c|}
\hline \multicolumn{3}{|l|}{ Other } \\
\hline $\mathrm{Age}^{\wedge}$ & $68(10.2)$ & \\
\hline Gender male & 121 & 41.6 \\
\hline$B M I^{*}$ & $26.8(4.9)$ & \\
\hline$\geq 30$ & 49 & 17.2 \\
\hline \multicolumn{3}{|l|}{ Major diagnosis* } \\
\hline Osteoarthritis & 279 & 95.5 \\
\hline Osteonecrosis & 3 & 1.0 \\
\hline Mechanical complications/infections & 9 & 3.1 \\
\hline \multicolumn{3}{|l|}{ Operations at joint before procedure* $\wedge$} \\
\hline 0 & 265 & 91.1 \\
\hline 1 & 19 & 6.5 \\
\hline 2 or more & 7 & 2.4 \\
\hline \multicolumn{3}{|l|}{ Marital status } \\
\hline Married & 192 & 66.4 \\
\hline Single & 25 & 8.7 \\
\hline Divorced/living apart & 34 & 11.8 \\
\hline Widowed & 38 & 13.1 \\
\hline \multicolumn{3}{|l|}{ Housing situation } \\
\hline Alone & 81 & 28.1 \\
\hline With partner & 146 & 50.7 \\
\hline With family & 61 & 21.2 \\
\hline Discharge home (other, inpatient rehabilitation) & 56 & 19.2 \\
\hline Health insurance compulsory (other, private) & 149 & 51.2 \\
\hline Already THR & 61 & 20.9 \\
\hline Preoperative hemoglobin* & $14.0(1.2)$ & \\
\hline Blood transfusion/erythrocyte concentrate* & 16 & 5.5 \\
\hline \multicolumn{3}{|l|}{ ASA score* } \\
\hline 1 & 110 & 37.7 \\
\hline 2 & 158 & 54.1 \\
\hline 3 or higher & 24 & 8.2 \\
\hline \multicolumn{3}{|l|}{ Charlson Comorbidity Index* } \\
\hline 0 & 217 & 74.6 \\
\hline 1 & 57 & 19.6 \\
\hline 2 & 10 & 3.4 \\
\hline 3 or higher & 7 & 2.4 \\
\hline Metabolic syndrome* & 8 & 2.7 \\
\hline Cement or hybrid (other, cementless)^ & 34 & 11.9 \\
\hline
\end{tabular}

QALY gains the most were age and preoperative WOMAC (or EQ-5D) score, which qualifies these parameters to be included in shared decision making with the patient for professionals. This makes a QALY threshold, but not a cost per QALY threshold, important for health policy related to THR.
As the WOMAC score and EQ-5D scores predict the patient benefit and QALY gains best, they should be used in patient reported outcome measures (PROMs) in the future. PROMs are becoming important as a quality measure from the patient's perspective and for pay for performance approaches. Because of the differentiation 
Table 2 Inpatient cost calculation

\begin{tabular}{|c|c|c|c|c|c|c|c|c|c|c|c|}
\hline Cost matrix* & Physicians & Nursing & $\begin{array}{r}\text { Medical/ } \\
\text { technical staff }\end{array}$ & $\begin{array}{r}\text { Drugs } \\
\text { general }\end{array}$ & Drugs individual & $\begin{array}{r}\text { Implants } \\
\text { and grafts }\end{array}$ & Material & $\begin{array}{r}\text { Material } \\
\text { individual }\end{array}$ & $\begin{array}{r}\text { Medical } \\
\text { infrastructure }\end{array}$ & $\begin{array}{r}\text { Non-medical } \\
\text { infrastructure }\end{array}$ & $\begin{array}{r}\text { All cost } \\
\text { categories }\end{array}$ \\
\hline Ward & 438 & 731 & 0 & 64 & 1 & 0 & 53 & 3 & 196 & 765 & 2,251 \\
\hline Intensive care & 7 & 18 & 0 & 3 & 0 & 0 & 4 & 0 & 1 & 6 & 40 \\
\hline Operating room & 434 & 0 & 306 & 6 & 0 & 1,709 & 165 & 64 & 162 & 229 & 3,075 \\
\hline Anesthesia & 242 & 0 & 153 & 22 & 0 & 0 & 49 & 0 & 29 & 69 & 563 \\
\hline Cardiac diagnostics & 1 & 0 & 0 & 0 & 0 & 0 & 0 & 9 & 0 & 0 & 10 \\
\hline Endoscopic diagnostics & 1 & 0 & 1 & 0 & 0 & 0 & 1 & 0 & 1 & 1 & 4 \\
\hline Radiology & 22 & 0 & 26 & 4 & 0 & 0 & 8 & 4 & 6 & 22 & 91 \\
\hline Laboratories & 2 & 0 & 36 & 6 & 11 & 0 & 32 & 8 & 4 & 12 & 111 \\
\hline Further diagnostics/therapy & 2 & 0 & 113 & 0 & 0 & 0 & 3 & 0 & 4 & 44 & 166 \\
\hline All cost-centers & 1,148 & 749 & 635 & 104 & 12 & 1,709 & 314 & 87 & 403 & 1,148 & 6,310 \\
\hline
\end{tabular}


Table 3 QALY calculation - separated by preoperative WOMAC score

\begin{tabular}{|c|c|c|c|c|c|c|c|c|c|c|c|c|c|c|c|c|c|c|}
\hline \multicolumn{19}{|c|}{ Visual analog scale (gold standard): VAS adjusted life years (VAS-AL) } \\
\hline $\begin{array}{r}\text { WOMAC } \\
\text { pre-operative }\end{array}$ & $\mathbf{N}$ & $\begin{array}{r}\text { Mean EQ- } \\
5 \mathrm{D} \text { VAS } \\
\text { pre- } \\
\text { operative }\end{array}$ & SD & $\begin{array}{r}\text { Mean EQ- } \\
\text { 5D VAS } \\
\text { post- } \\
\text { operative }\end{array}$ & SD & $\begin{array}{r}\text { Mean } \\
\text { change } \\
\text { EQ-5D } \\
\text { VAS }\end{array}$ & SD & $\begin{array}{r}\text { Life } \\
\text { expectancy }\end{array}$ & SD & $\begin{array}{c}\text { Mean } \\
\text { costs } \\
\text { in } €\end{array}$ & SD & $\begin{array}{r}\text { Mean costs } \\
\text { incl. potential } \\
\text { revision }\end{array}$ & SD & $\begin{array}{r}\text { VAS- } \\
\text { AL }\end{array}$ & SD & $\begin{array}{r}\text { VAS-AL } \\
\text { disc. } 3.5 \%\end{array}$ & $\begin{array}{r}\text { Cost/VAS-AL } \\
\text { in } €\end{array}$ & $\begin{array}{r}\text { Cost/VAS-AL } \\
\text { disc. } 3.5 \%\end{array}$ \\
\hline $0-20$ & 14 & 47.50 & 21.68 & 74.86 & 16.49 & 27.36 & 23.26 & 16.48 & 7.95 & 7,043 & 1,813 & 8,421 & 1,778 & 4.10 & 3.25 & 3.38 & 2,055 & 2,313 \\
\hline $21-40$ & 75 & 50.09 & 22.85 & 71.99 & 22.07 & 21.89 & 27.63 & 16.71 & 8.68 & 6,698 & 1,860 & 8,100 & 2,304 & 4.46 & 6.93 & 2.73 & 1,816 & 2,737 \\
\hline $41-60$ & 110 & 59.19 & 17.86 & 78.10 & 19.95 & 18.91 & 22.82 & 17.16 & 7.9 & 6,198 & 1,036 & 7,582 & 1,843 & 3.25 & 4.88 & 2.41 & 2,332 & 2,892 \\
\hline $61-80$ & 77 & 68.09 & 16.48 & 83.31 & 12.44 & 15.22 & 20.35 & 18.58 & 7.16 & 6,034 & 978 & 7,487 & 1,419 & 2.79 & 3.99 & 2.05 & 2,684 & 3,310 \\
\hline $81-100$ & 16 & 79.69 & 16.23 & 86.63 & 10.79 & 6.94 & 17.55 & 20.39 & 7.61 & 5,948 & 617 & 7,568 & 1,118 & 2.27 & 4.73 & 1.00 & 3,337 & 6,757 \\
\hline Sum & 292 & 59.76 & 20.72 & 78.22 & 18.78 & 18.45 & 23.55 & 17.57 & 7.92 & 6,310 & 1,341 & 7,730 & 1,854 & 3.43 & 5.23 & 2.39 & 2,256 & 2,964 \\
\hline \multicolumn{19}{|c|}{ UK preference-weighted index as underlying value set (QALY) } \\
\hline $\begin{array}{l}\text { WOMAC pre- } \\
\text { operative }\end{array}$ & $\mathrm{N}$ & $\begin{array}{l}\text { Mean EQ- } \\
\text { 5D utility } \\
\text { score pre- } \\
\text { operative }\end{array}$ & SD & $\begin{array}{r}\text { Mean EQ- } \\
\text { 5D utility } \\
\text { score } \\
\text { post- } \\
\text { operative }\end{array}$ & SD & $\begin{array}{l}\text { Mean } \\
\text { change } \\
\text { EQ-5D } \\
\text { utility } \\
\text { score }\end{array}$ & SD & $\begin{array}{r}\text { Life } \\
\text { expectancy }\end{array}$ & SD & $\begin{array}{c}\text { Mean } \\
\text { costs } \\
\text { in } €\end{array}$ & SD & $\begin{array}{r}\text { Mean costs } \\
\text { incl. potential } \\
\text { revision }\end{array}$ & SD & QALY & SD & $\begin{array}{r}\text { QALY } \\
\text { disc. } 3.5 \%\end{array}$ & $\begin{array}{r}\text { Cost/QALY } \\
\text { in } €\end{array}$ & $\begin{array}{r}\text { Cost/QALY } \\
\text { disc. } 3.5 \%\end{array}$ \\
\hline $0-20$ & 14 & 0.04 & 0.12 & 0.81 & 0.17 & 0.77 & 0.16 & 16.48 & 7.95 & 7,043 & 1,813 & 8,421 & 1,778 & 12.40 & 6.17 & 9.50 & 679 & 823 \\
\hline $21-40$ & 75 & 0.30 & 0.31 & 0.76 & 0.25 & 0.46 & 0.33 & 16.71 & 8.68 & 6,698 & 1,860 & 8,100 & 2,304 & 8.20 & 8.78 & 5.76 & 987 & 1,300 \\
\hline $41-60$ & 110 & 0.54 & 0.25 & 0.86 & 0.15 & 0.31 & 0.28 & 17.16 & 7.90 & 6,198 & 1,036 & 7,582 & 1,843 & 5.85 & 6.77 & 3.98 & 1,295 & 1,751 \\
\hline $61-80$ & 77 & 0.70 & 0.17 & 0.88 & 0.16 & 0.18 & 0.24 & 18.58 & 7.16 & 6,034 & 978 & 7,487 & 1,419 & 3.28 & 4.64 & 2.40 & 2,281 & 2,829 \\
\hline $81-100$ & 16 & 0.80 & 0.06 & 0.94 & 0.10 & 0.14 & 0.14 & 20.39 & 7.61 & 5,948 & 617 & 7,568 & 1,118 & 3.16 & 2.81 & 2.03 & 2,393 & 3,329 \\
\hline Sum & 292 & 0.51 & 0.30 & 0.84 & 0.19 & 0.33 & 0.31 & 17.57 & 7.92 & 6,310 & 1,341 & 7,730 & 1,854 & 5.95 & 7.08 & 4.25 & 1,300 & 1,669 \\
\hline \multicolumn{19}{|c|}{ German experience-weighted index as underlying value set (EB-QALY) } \\
\hline $\begin{array}{r}\text { WOMAC pre- } \\
\text { operative }\end{array}$ & $\mathbf{N}$ & $\begin{array}{l}\text { Mean EQ- } \\
\text { 5D utility } \\
\text { score pre- } \\
\text { operative }\end{array}$ & SD & $\begin{array}{r}\text { Mean EQ- } \\
5 \mathrm{D} \text { utility } \\
\text { score } \\
\text { post- } \\
\text { operative }\end{array}$ & SD & $\begin{array}{l}\text { Mean } \\
\text { change } \\
\text { EQ-5D } \\
\text { utility } \\
\text { score }\end{array}$ & SD & $\begin{array}{r}\text { Life } \\
\text { expectancy }\end{array}$ & SD & $\begin{array}{r}\text { Mean } \\
\text { costs } \\
\text { in } €\end{array}$ & SD & $\begin{array}{r}\text { Mean costs } \\
\text { incl. potential } \\
\text { revision }\end{array}$ & SD & $\begin{array}{l}\text { EB- } \\
\text { QALY }\end{array}$ & SD & $\begin{array}{r}\text { EB-QALY } \\
\text { disc. } 3.5 \%\end{array}$ & $\begin{array}{l}\text { Cost/EB- } \\
\text { QALY in } €\end{array}$ & $\begin{array}{r}\text { Cost/EB- } \\
\text { QALY disc. } \\
3.5 \%\end{array}$ \\
\hline $0-20$ & 14 & 0.34 & 0.06 & 0.72 & 0.17 & 0.39 & 0.15 & 16.48 & 7.95 & 7,043 & 1,813 & 8,421 & 1,778 & 6.49 & 4.60 & 4.76 & 1,297 & 1,643 \\
\hline $21-40$ & 75 & 0.44 & 0.13 & 0.71 & 0.18 & 0.27 & 0.18 & 16.71 & 8.68 & 6,698 & 1,860 & 8,100 & 2,304 & 4.71 & 5.09 & 3.39 & 1,721 & 2,207 \\
\hline $41-60$ & 110 & 0.53 & 0.12 & 0.77 & 0.14 & 0.24 & 0.17 & 17.16 & 7.90 & 6,198 & 1,036 & 7,582 & 1,843 & 4.39 & 4.17 & 3.04 & 1,726 & 2,292 \\
\hline $61-80$ & 77 & 0.65 & 0.12 & 0.80 & 0.12 & 0.15 & 0.17 & 18.58 & 7.16 & 6,034 & 978 & 7,487 & 1,419 & 2.79 & 3.62 & 2.02 & 2,685 & 3,368 \\
\hline $81-100$ & 16 & 0.73 & 0.08 & 0.86 & 0.06 & 0.12 & 0.11 & 20.39 & 7.61 & 5,948 & 617 & 7,568 & 1,118 & 2.59 & 2.20 & 1.75 & 2,920 & 3,856 \\
\hline Sum & 292 & 0.54 & 0.16 & 0.76 & 0.15 & 0.22 & 0.18 & 17.57 & 7.92 & 6,310 & 1,341 & 7,730 & 1,854 & 4.05 & 4.32 & 2.90 & 1,908 & 2,439 \\
\hline
\end{tabular}


Table 4 Multivariate regression analysis on costs and QALY gains

\begin{tabular}{|c|c|c|c|c|}
\hline Dependent variable: QALYs (U.K. preference-weighted) & Coefficient & Beta & SE & $\mathrm{p}$-value \\
\hline Constant & 43.810 & & 3.130 & .000 \\
\hline Preoperative WOMAC sum & -.153 & -.396 & .018 & .000 \\
\hline ICD F32 - Depression & -3.266 & -.096 & 1.597 & .042 \\
\hline G47 - Sleep disorder & -4.843 & -.109 & 2.327 & .038 \\
\hline Reflux & -2.645 & -.094 & 1.337 & .049 \\
\hline Major hip distortion & -3.770 & -.140 & 1.290 & .004 \\
\hline OPS 8-930/1 - Monitoring & 2.709 & .107 & 1.334 & .043 \\
\hline Age & -.331 & -.466 & .034 & .000 \\
\hline \multicolumn{5}{|l|}{$\mathrm{n}=271$ Adj. $\mathrm{R}^{2}=.418$} \\
\hline Dependent variable: QALYs (U.K. preference-weighted) & Coefficient & Beta & SE & p-value \\
\hline Constant & 42.268 & & 2.240 & .000 \\
\hline Preoperative EQ-5D utility score (U.K. preference-weighted) & -15.316 & -.658 & .805 & .000 \\
\hline ICD F32 - Depression & -2.673 & -.078 & 1.176 & .024 \\
\hline Reflux & -1.829 & -.065 & .970 & .060 \\
\hline Major hip distortion & -3.205 & -.119 & .946 & .001 \\
\hline Age & -.318 & -.447 & .026 & .000 \\
\hline ASA 2 (compared to ASA 1) & -846 & -.060 & .498 & .090 \\
\hline \multicolumn{5}{|l|}{$\mathrm{n}=271$ Adj. $\mathrm{R}^{2}=.685$} \\
\hline Dependent variable: inpatient costs & Coefficient & Beta & SE & p-value \\
\hline Constant & 6,338 & & 845 & .000 \\
\hline Preoperative EQ-5D utility score (U.K. preference-weighted) & -426 & -.109 & 177 & .017 \\
\hline ICD J45 - Asthma & -508 & -.085 & 274 & .065 \\
\hline Number of secondary diagnoses & 103 & .242 & 25 & .000 \\
\hline OPS 5-782 - Excision/resection of diseased bone & 1,435 & .147 & 468 & .002 \\
\hline OPS 5-791 - Open reposition of fracture & 1,699 & .194 & 401 & .000 \\
\hline OPS 5-821 - Revision & 1,811 & .185 & 462 & .000 \\
\hline OPS 8-930/1 - Monitoring & -686 & -.162 & 233 & .004 \\
\hline Number of operations and procedures & 461 & .409 & 63 & .000 \\
\hline Age & -11 & -.098 & 5 & .038 \\
\hline BMl & 25 & .105 & 10 & .018 \\
\hline Preoperative hemoglobin & -83 & -.081 & 47 & .079 \\
\hline $\mathrm{n}=271 \mathrm{Adj} . \mathrm{R}^{2}=.502$ & & & & \\
\hline
\end{tabular}

by preoperative WOMAC, results can support patients in their decisions on THR, they can support health policy with prioritization decisions based on QALY thresholds and net benefit analysis based on willingness to pay, and they can support hospital management through a differentiated analysis of costs (Table 2) and the impact of patient and care selection on costs and QALY gains (Table 4). Age is the second driver of QALY gains. Similar to other studies on THR cost-effectiveness [33,45], age has a low impact on the EQ-5D change score itself (younger people expect slightly higher health benefits from THR), but it affects the life expectancy component of QALY calculation. Still, all WOMAC and age groups benefit from THR and have low costs per QALY (Tables 3 and 5). THR is a cost-effective intervention for all analyzed WOMAC and age groups when applying the common cost per QALY thresholds from NICE, the World Health Organization, and other institutions that provide national guidance and advice on improving health care $[21,46]$.

The advantages of ACER analysis in this study, according to Bang and Zhao [47], are that (1) clinical and economical characteristics of THR are analyzed independently of an alternative or no intervention; (2) ACER results are thus intuitive for research and policy; (3) results are more robust compared with ICER; and (4) a 
Table 5 QALY gains by age

\begin{tabular}{lcccc}
\hline Underlying value set & \multicolumn{5}{c}{ Age group } \\
\cline { 2 - 5 } & \multicolumn{5}{c}{$\mathbf{5 9}$} & $\mathbf{6 0 - 6 9}$ & $\mathbf{7 0 - 7 9}$ & $\geq \mathbf{8 0}$ \\
\hline & \multicolumn{5}{c}{ QALYs } \\
VAS-AL based & 6.398 & 3.280 & 1.697 & 0.990 \\
UK QALY based & 10.967 & 6.122 & 4.341 & 2.531 \\
German EB-QALY based & 7.565 & 4.098 & 2.583 & 1.506 \\
& \multicolumn{5}{c}{ QALYs discounted 3.5\% } \\
VAS-AL based & 3.922 & 2.357 & 1.953 & 0.860 \\
UK QALY based & 6.723 & 4.399 & 3.105 & 2.199 \\
German EB-QALY based & 4.637 & 2.944 & 2.269 & 1.308 \\
& \multicolumn{5}{c}{ Cost/QALY in € } \\
VAS-AL based & 1.927 & 3.085 & 3.771 & 9.391 \\
UK QALY based & 1.124 & 1.653 & 2.372 & 3.672 \\
German EB-QALY based & 1.630 & 2.469 & 3.246 & 6.171 \\
& Cost/QALY in €; discounted $\mathbf{3 . 5} \%$ \\
VAS-AL based & 1.738 & 2.857 & 3.569 & 9.071 \\
UK QALY based & 1.014 & 1.530 & 2.245 & 3.547 \\
German EB-QALY based & 1.470 & 2.286 & 3.072 & 5.961 \\
\hline
\end{tabular}

subjective cost per QALY threshold is not needed for decision making. Further advantages of the study were, first, the detailed bottom-up costing approach for each patient that was based on the actual resource use of each single patient. The costing method is verifiable and comparable, as each case had to pass plausibility checks by the InEK to be part of the study [26]. The separation of costs into components (Table 2) enables comparative and transparent costing analyses. Second, the prospective study design allowed the attribution of actual patient costs to health outcome scores to calculate cost-utility (QALY) for each patient. Thus, it is the first German study to report cost-effectiveness or cost-utility values for THR. The calculation of EB-QALYs and VAS-ALs besides QALYs has the advantage that - although they do not conform to the rigorous QALY definition - EBQALYs and VAS-ALs are closer to the actual experiences of THR patients than QALYs but still have the advantages of QALY calculation.

Limitations of the study include: (1) inability to retrieve health states after a potential revision or for longer follow-up periods. Thus, we extrapolated the EQ-5D utility score change of the 6-month follow-up for QALY calculation. In this way, we assume that the change score remains constant during each patient's individual life expectancy. This assumption is rather conservative, as the literature shows that HRQoL for THR patients is slightly higher a year after operation compared with at the 6month follow-up [48]. However, this method is widely accepted and used in the literature [5,48]; (2) the EQ-5D change scores of revision patients differed slightly from

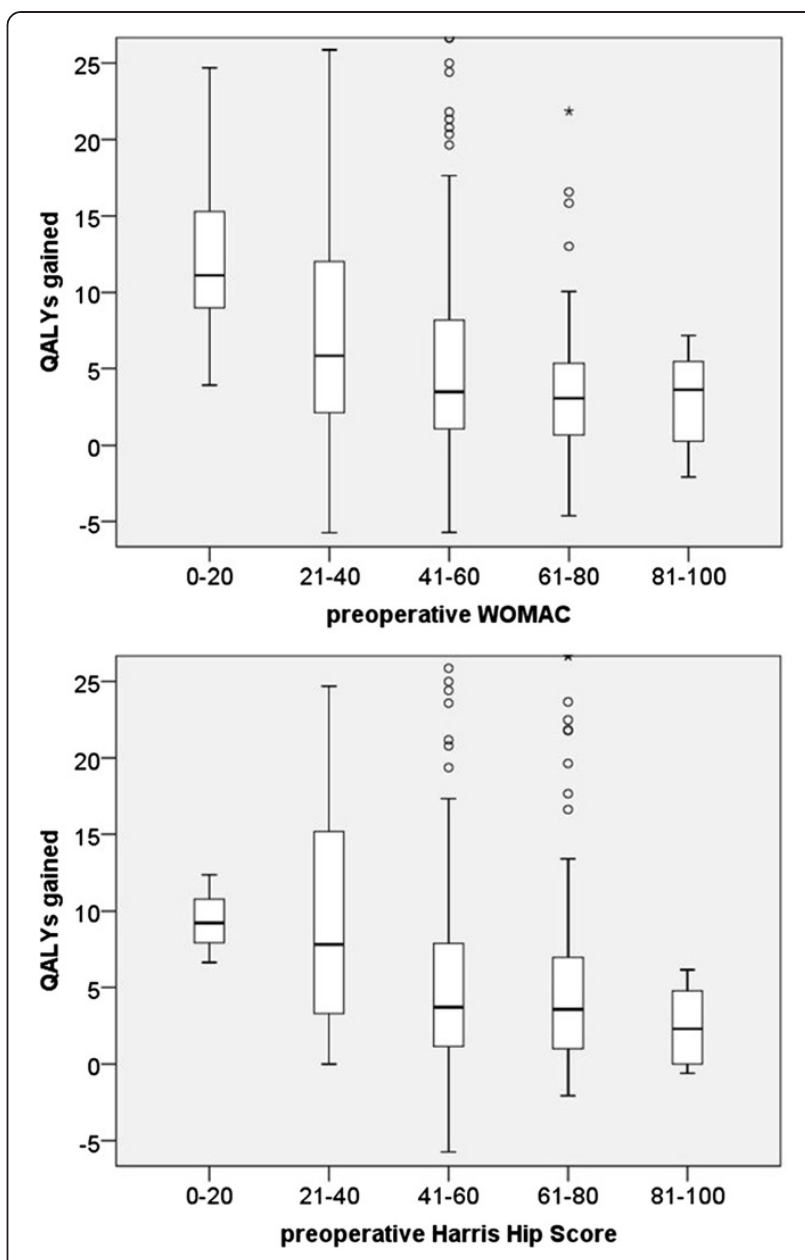

Figure 1 QALYs by preoperative WOMAC and harris hip score.

primary THR change scores $(-0.02)$ in our study. Similar to other studies, we assumed that revisions keep the change in HRQoL at the 6-month follow-up level [5]; (3) $18 \%$ of patients were lost in the follow-up. They did not differ significantly in preoperative socio-demographic and medical factors. However, similar to other THR studies [5], they had slightly lower mean preoperative EQ-5D scores $(-0.01$ with the experience-weighted index), which indicates a conservative estimate and a slightly higher EQ$5 \mathrm{D}$ change score if these patients were included in the study. As we have a monocentric study, representativeness of patients might not be given; (4) we used the WOMAC as a preoperative patient characteristic for health state and dysfunction for categorizing QALY results. However, as WOMAC and EQ-5D utility scores are correlated, we could not eliminate the general limitation of regression toward the mean, potentially leading to inaccurate results when comparing preoperative patient groups on costs and QALYs. The use of WOMAC in standardized PROMs is more likely anyway, as disease specific instruments such as the Oxford Hip/Knee Score are already used for 
prioritization in the U.K. [6]; and (5) the inpatient cost accounting scheme used had some minor limitations $[26,42]$. The full-cost approach did not include capital costs, and although German DRG costing has a high accuracy, it is not the gold standard in every calculation step.

In comparison with other cost-effectiveness literature, our results range as follows: average QALY gains were similar to many U.K. and U.S. studies $[5,33,49,50]$. However, especially in methodologically similar UK studies, average preoperative health scores are lower compared with this study, allowing a higher increase in scores [5]. Here, we suppose an operation at an earlier coxarthrosis stage in Germany than in the U.K. Costs per QALY were mostly similar $[5,33]$ or lower $[20,21,49]$ compared with methodologically comparable studies.

In a future perspective, studies should take a closer look at the actual comparative group of THR patients. In this study, we identified the preoperative WOMAC score as a good predictor of QALY gains. However, similar to most other studies, we compared with a virtual group of patients with no intervention and assumed that their health state remained at the level of THR patients before operation. This might under- or overestimate the real benefit of THR compared with no intervention or compared with pain relief instead of THR [51]. Thus, WOMAC and health outcomes should be analyzed for patients who decided against THR compared with THR patients. A separation into preoperative WOMAC groups, as in this study, can then show which patients benefit most and for which patients cost-utility is highest with conservative therapy. A matching of pre- and postoperative EQ-5D values with population normative values can quantify the utility of total hip replacement for preoperative health state groups. Finally, a comparison of patient reported outcome measures and related micro-costing with other countries allows a detailed comparison of cost-effectiveness and possibly conclusions on weakness in the health care system.

\section{Conclusions}

The WOMAC score and the EQ-5D score before operation were the most important predictors of QALY gains. The poorer the WOMAC score or the EQ-5D score before operation, the higher the patient benefit. Although differences in QALY gains and costs per QALY were high between the three methodologies of costutility analysis, they were far below common thresholds in all preoperative utility score groups and with all underlying calculation methodologies [21,46]. CER results might be used in pay for performance approaches for an efficient and effective health care system [52]. Health outcome and micro-costing measures in combination are useful performance measures to compare hospitals on a patient-level basis. CER results support patients in a shared decision making situation before THR based on a personalized risk assessment approach. They support prioritization decisions in health policy concerning preoperative health states. And they support hospital management through differentiated costing and health outcome measures on a patient basis.

\begin{abstract}
Abbreviations
ACER: Average cost-effectiveness ratio; ASA: American Society of

Anesthesiologists; CER: Comparative effectiveness research; DRG: Diagnosis related group; HRQoL: Health-related quality of life; EB-QALY:

Experience-based quality-adjusted life year; EQ-5D: EuroQol 5-dimension; EQ-5D VAS: EuroQol 5-dimension visual analogue scale; ICER: Incremental cost-effectiveness ratio; InEK: Institute for the Hospital Remuneration System; NICE: National Institute of Health and Care Excellence; NHS: National Health Service; OLS: Ordinary least squares; PROMs: Patient-reported outcome measures; THR: Total hip replacement; TTO: Time trade-off; QALY: Quality-adjusted life year; VAS-AL: Visual analogue scale adjusted life years; WOMAC: Western Ontario and McMaster Universities Arthritis Index.
\end{abstract}

\section{Competing interests}

The authors declare that they have no competing interests.

\section{Authors' contributions}

MV and WP designed the study and drafted the manuscript. MV performed the statistical analyses. RW and CL acquired the data and helped to draft the manuscript. All authors read and approved the final manuscript.

\section{Author details}

'Helmholtz Zentrum München, German Research Center for Environmental Health, Institute of Health Economics and Health Care Management, P.O. Box 1129, Neuherberg 85758, Germany. ${ }^{2}$ Ludwig-Maximilians-Universität

München, Munich School of Management, Institute of Health Economics and Health Care Management \& Munich Center of Health Sciences, Munich, Germany. ${ }^{3}$ Department of Orthopaedics and Trauma Surgery, Krankenhaus Barmherzige Brüder München, Akademisches Lehrkrankenhaus der Technischen Universität München, Romanstraße 93, Munich 80639, Germany.

${ }^{4}$ Klinikum rechts der Isar, Technical University Munich, Munich, Germany.

Received: 3 February 2014 Accepted: 7 August 2014

Published: 15 August 2014

\section{References}

1. Kurtz S, Ong K, Lau E, Mowat F, Halpern M: Projections of primary and revision hip and knee arthroplasty in the United States from 2005 to 2030. J Bone Joint Surg Am 2007, 89(4):780-785.

2. OECD: Health at a Glance Europe. 2012, http://www.oecd.org/els/healthsystems/HealthAtAGlanceEurope2012.pdf.

3. Gesundheitsberichterstattung des Bundes: Die 50 häufigsten Operationen der vollstationären Patientinnen und Patienten in Krankenhäusern. http:// www.gbe-bund.de/oowa921-install/servlet/oowa/aw92/dboowasys921. xwdevkit/xwd_init?gbe.isgbetol/xs_start_neu/\&p_aid=i\&p_aid=34158371\& nummer $=666 \&$ _p_sprache $=D \& p \_i n d s p=99999999 \&$ __aid $=25608545$.

4. Learmonth ID, Young $C$, Rorabeck C: The operation of the century: total hip replacement. Lancet 2007, 370(9597):1508-1519.

5. Jenkins PJ, Clement ND, Hamilton DF, Gaston P, Patton JT, Howie CR: Predicting the cost-effectiveness of total hip and knee replacement: a health economic analysis. Bone Joint J 2013, 95-B(1):115-121.

6. Dakin H, Gray A, Fitzpatrick R, Maclennan G, Murray D: Rationing of total knee replacement: a cost-effectiveness analysis on a large trial data set. BMJ Open 2012, 2(1):e000332.

7. Dall GF, Ohly NE, Ballantyne JA, Brenkel IJ: The influence of pre-operative factors on the length of in-patient stay following primary total hip replacement for osteoarthritis: a multivariate analysis of 2302 patients. $J$ Bone Joint Surg (Br) 2009, 91(4):434-440.

8. Biring GS, Masri BA, Greidanus NV, Duncan CP, Garbuz DS: Predictors of quality of life outcomes after revision total hip replacement. J Bone Joint Surg (Br) 2007, 89(11):1446-1451. 
9. Davis AM, Agnidis Z, Badley E, Kiss A, Waddell JP, Gross AE: Predictors of functional outcome two years following revision hip arthroplasty. J Bone Joint Surg Am 2006, 88(4):685-691.

10. Fortin PR, Clarke AE, Joseph L, Liang MH, Tanzer M, Ferland D, Phillips C, Partridge AJ, Belisle P, Fossel AH, Mahomed N, Sledge CB, Katz JN: Outcomes of total hip and knee replacement: preoperative functional status predicts outcomes at six months after surgery. Arthritis Rheum 1999, 42(8):1722-1728.

11. Hawker GA, Badley EM, Borkhoff CM, Croxford R, Davis AM, Dunn S, Gignac MA, Jaglal SB, Kreder HJ, Sale JE: Which patients are most likely to benefit from total joint arthroplasty? Arthritis Rheum 2013, 65(5):1243-1252.

12. Nilsdotter AK, Lohmander LS: Age and waiting time as predictors of outcome after total hip replacement for osteoarthritis. Rheumatology (Oxford) 2002, 41(11):1261-1267.

13. Nilsdotter AK, Petersson IF, Roos EM, Lohmander LS: Predictors of patient relevant outcome after total hip replacement for osteoarthritis: a prospective study. Ann Rheum Dis 2003, 62(10):923-930.

14. Roder C, Parvizi J, Eggli S, Berry DJ, Muller ME, Busato A: Demographic factors affecting long-term outcome of total hip arthroplasty. Clin Orthop Relat Res 2003, 417:62-73.

15. Roder C, Staub LP, Eggli S, Dietrich D, Busato A, Muller U: Influence of preoperative functional status on outcome after total hip arthroplasty. J Bone Joint Surg Am 2007, 89(1):11-17.

16. Santaguida PL, Hawker GA, Hudak PL, Glazier R, Mahomed NN, Kreder HJ, Coyte PC, Wright JG: Patient characteristics affecting the prognosis of total hip and knee joint arthroplasty: a systematic review. Can J Surg 2008, 51(6):428-436.

17. Young NL, Cheah D, Waddell JP, Wright JG: Patient characteristics that affect the outcome of total hip arthroplasty: a review. Can J Surg 1998 41(3):188-195.

18. Bozic KJ, Katz P, Cisternas M, Ono L, Ries MD, Showstack J: Hospital resource utilization for primary and revision total hip arthroplasty. J Bone Joint Surg Am 2005, 87(3):570-576.

19. Antoniou J, Martineau PA, Filion KB, Haider S, Zukor DJ, Huk OL, Pilote L, Eisenberg MJ: In-hospital cost of total hip arthroplasty in Canada and the United States. J Bone Joint Surg Am 2004, 86-A(11):2435-2439.

20. Chang RW, Pellisier JM, Hazen GB: A cost-effectiveness analysis of total hip arthroplasty for osteoarthritis of the hip. JAMA 1996, 275(11):858-865.

21. Daigle ME, Weinstein AM, Katz JN, Losina E: The cost-effectiveness of total joint arthroplasty: a systematic review of published literature. Best Pract Res Clin Rheumatol 2012, 26(5):649-658.

22. Stargardt T: Health service costs in Europe: cost and reimbursement of primary hip replacement in nine countries. Health Econ 2008, 17(1 Suppl):S9-S20.

23. Rawlins MD, Culyer AJ: National Institute for Clinical Excellence and its value judgments. BMJ 2004, 329(7459):224-227.

24. Giacomini M: How good is good enough? Standards in policy decisions to cover new health technologies. Healthc Policy 2007, 3(2):91-101.

25. Altman DG: Systematic reviews of evaluations of prognostic variables. BMJ 2001, 323(7306):224-228.

26. Vogl M: Assessing DRG cost accounting with respect to resource allocation and tariff calculation: the case of Germany. Heal Econ Rev 2012, 2(1):15.

27. Leidl R, Reitmeir P: A value set for the EQ-5D based on experienced health states: development and testing for the German population. PharmacoEconomics 2011, 29(6):521-534.

28. Statistisches Bundesamt [Federal Statistical Office]: Periodensterbetafeln für Deutschland [Life Tables for Germany]. https://www.destatis.de/DE/ Publikationen/Thematisch/Bevoelkerung/Bevoelkerungsbewegung/ PeriodensterbetafelnBundeslaender.html.

29. Whitehead SJ, Ali S: Health outcomes in economic evaluation: the QALY and utilities. Br Med Bull 2010, 96:5-21.

30. Robinson $A H$, Palmer $C R$, Villar RN: Is revision as good as primary hip replacement? A comparison of quality of life. J Bone Joint Surg (Br) 1999, 81(1):42-45

31. Patil S, Garbuz DS, Greidanus NV, Masri BA, Duncan CP: Quality of life outcomes in revision vs primary total hip arthroplasty: a prospective cohort study. J Arthroplast 2008, 23(4):550-553.

32. Engesaeter LB, Engesaeter IO, Fenstad AM, Havelin LI, Karrholm J, Garellick $G$, Pedersen $A B$, Overgaard S: Low revision rate after total hip arthroplasty in patients with pediatric hip diseases. Acta Orthop 2012, 83(5):436-441.
33. Pennington M, Grieve $R$, Sekhon JS, Gregg P, Black N, van der Meulen JH: Cemented, cementless, and hybrid prostheses for total hip replacement: cost effectiveness analysis. BMJ 2013, 346:f1026.

34. Hershey JC, Asch DA, Jepson C, Baron J, Ubel PA: Incremental and average cost-effectiveness ratios: will physicians make a distinction? Risk Anal 2003, 23(1):81-89.

35. Deutsche Gesellschaft für Unfallchirurgie: Leitlinien der Deutschen Gesellschaft für Unfallchirurgie - Endoprothese bei Koxarthrose. http:// www.awmf.org/uploads/tx_szleitlinien/012-006l_S1_Endoprothese_bei_ Koxarthrose 2008.pdf.

36. Dolan P: Modelling valuations for health states: the effect of duration Health Policy 1996, 38(3):189-203.

37. Barton GR, Sach TH, Avery AJ, Doherty M, Jenkinson C, Muir KR: Comparing the performance of the EQ-5D and SF-6D when measuring the benefits of alleviating knee pain. Cost Eff Resour Alloc 2009, 7:12.

38. Ostendorf M, van Stel HF, Buskens E, Schrijvers AJ, Marting LN, Verbout AJ, Dhert WJ: Patient-reported outcome in total hip replacement. A comparison of five instruments of health status. J Bone Joint Surg (Br) 2004, 86(6):801-808.

39. Veenhof C, Bijlsma JW, van den Ende CH, van Dijk GM, Pisters MF, Dekker J: Psychometric evaluation of osteoarthritis questionnaires: a systematic review of the literature. Arthritis Rheum 2006, 55(3):480-492.

40. Stucki G, Meier D, Stucki S, Michel BA, Tyndall AG, Dick W, Theiler R: Evaluation of a German version of WOMAC (Western Ontario and McMaster Universities) Arthrosis Index. Z Rheumatol 1996, 55(1):40-49.

41. Roos EM, Klassbo M, Lohmander LS: WOMAC osteoarthritis index. Reliability, validity, and responsiveness in patients with arthroscopically assessed osteoarthritis. Western Ontario and MacMaster Universities. Scand J Rheumatol 1999, 28(4):210-215.

42. Vogl M: Improving patient-level costing in the English and the German 'DRG' system. Health Policy 2013, 109(3):290-300.

43. Bland JM, Altman DG: Regression towards the mean. BMJ 1994, 308(6942):1499.

44. Geissler A, Scheller-Kreinsen D, Quentin W: Do diagnosis-related groups appropriately explain variations in costs and length of stay of hip replacement? A comparative assessment of DRG systems across 10 European countries. Health Econ 2012, 21(Suppl 2):103-115.

45. Rissanen P, Aro S, Sintonen H, Asikainen K, Slatis P, Paavolainen P: Costs and cost-effectiveness in hip and knee replacements. A prospective study. Int J Technol Assess Health Care 1997, 13(4):575-588.

46. McCabe C, Claxton K, Culyer AJ: The NICE cost-effectiveness threshold: what it is and what that means. PharmacoEconomics 2008, 26(9):733-744.

47. Bang $\mathrm{H}$, Zhao $\mathrm{H}$ : Average cost-effectiveness ratio with censored data. J Biopharm Stat 2012, 22(2):401-415.

48. Ethgen O, Bruyere O, Richy F, Dardennes C, Reginster JY: Health-related quality of life in total hip and total knee arthroplasty. A qualitative and systematic review of the literature. J Bone Joint Surg Am 2004, 86-A(5):963-974.

49. James $\mathrm{M}$, St Leger $\mathrm{S}$, Rowsell KV: Prioritising elective care: a cost utility analysis of orthopaedics in the north west of England. J Epidemiol Community Health 1996, 50(2):182-189.

50. Bozic KJ, Saleh KJ, Rosenberg AG, Rubash HE: Economic evaluation in total hip arthroplasty: analysis and review of the literature. J Arthroplast 2004, 19(2):180-189

51. National Institute for Health and Care Excellence (NICE): Osteoarthritis The care and management of osteoarthritis in adults. http://www.nice.org.uk/ nicemedia/pdf/cg59niceguideline.pdf.

52. Porter ME: What is value in health care? N Engl J Med 2010, 363(26):2477-2481.

doi:10.1186/1472-6963-14-342

Cite this article as: Vogl et al:: The impact of preoperative patient characteristics on the cost-effectiveness of total hip replacement: a cohort study. BMC Health Services Research 2014 14:342. 